\title{
Listric normal fault profiles: calculation using bed-length balance and fault displacement
}

\author{
IAN DAVISON \\ Curso de Pós-Graduaçāo em Geologia. Universidade Federal da Bahia, Salvador, Brazil \\ (Received 14 May 1985; accepted in revised form 15 August 1985)
}

\begin{abstract}
A bed-length balance technique is presented to calculate listric normal fault trajectories using roll-over geometry and fault displacements. The technique can also be applied to subsidiary listric normal fault fans above a major fault to calculate the major listric fault geometry.
\end{abstract}

\section{INTRODUCTION}

THE IMPORTANCE of listric faulting in extensional tectonics is now widely recognized (e.g. Gibbs 1983, 1984, Wernicke \& Burchfiel 1982). Accurate calculation of listric normal fault profiles using roll-over shapes can have important applications in both the oil and mining industries. Verrall (1981) made the first important contribution to the calculation of listric fault shape by assuming similar folding in the hangingwall (Fig. 1a).

The method described in this paper assumes a flexuralslip model (Fig. 1b). Flexural-slip folding requires that the net-slip on the fault decreases from the surface downwards, thus causing contractional internal strain at depth in the hangingwall. Observation of several natural examples of roll-over profiles which do not show bedthickness changes in the hangingwall indicate the model may be appropriate in certain cases.

\section{BED-LENGTH BALANCING TECHNIQUE}

\section{Single listric faults}

The bed-length balance construction used here, which assumes flexural-slip folding in the hangingwall, is shown using a naturally deformed example in Fig. 1(b). The construction is as follows: a vertical line is drawn from point $\mathrm{A}$ to meet the regional dip line, $\mathrm{XY}$, at $\mathrm{B}$. Arc length la (horizontal displacement across the fault) is laid out along the downfaulted bed from $\mathrm{A}$ to define point $C$. A vertical line is then drawn from point $C$ to meet $\mathrm{XY}$ at $\mathrm{D}$; this line defines a horizontal distance, $\mathrm{BD}$ which is equal to $l b$. Arc length $l b$ is laid out from point $C$ to define-point $E$, and so on, until the last arc length laid out lies parallel to XY ( $l h$ in Fig. 1b). This arc length should now equal the original estimation of horizontal extension on the fault ( $/ h$ in Fig. 1c). A comparison of the two derived values of $l h$ provides a useful cross-check on the accuracy of the bed-length balance construction. Points BC, DE . . . LM are now joined together. These individual lines must define the fault trajectory as point
$B$ has now moved to point $C$ and point $D$ to $E$, etc. Joining the lines 'head-to-tail gives the fault profile shown in Fig. 1(b). The profile using Verrall's method and the profile calculated using the method described here are compared in Fig. 1(d). The depth to the décollement level, that is, the depth to where the fault becomes horizontal, calculated using the area balance technique is also marked in Fig. 1(d). Gibbs (1983) indicated that the area at the end of the section which corresponds to $A$ in Fig. 1(e) is generally not a simple rectangle but a more complex shape (B) with angular shear involved. In this case the area $\mathrm{A}$ divided by the calculated extension of the section usually overestimates the depth to décollement level. However, in the flexural-slip model a simple rectangle of excess area is produced at the end of the section ( $\mathrm{C}$ in Fig. 1e) and the depth to the décollement level using the equation in Fig. 1(c) should be a good estimate of the true depth. In fact, the two depths agree closely in the natural example shown (Fig. 1d).

\section{Listric fault fans above the main fault}

An additional complication which may and often does arise, is where a listric fan of synthetic or antithetic normal faults is developed along with a roll-over (Fig. 1f). The basic method used in this case is the same as that shown in Fig. 1(b), but the resultant movement on the main listric fault alone must be calculated. The displacement due to the subsidiary listric faults must be removed by restoring the marker bed back to a smooth curve. This can be done by bed-length balance to obtain the smooth curve, $\mathrm{AB}$. The curve $\mathrm{AB}$ must now be shifted parallel to the regional dip of the marker bed until point $A$ touches the main listric fault. $A B$ should now be in the position $A^{\prime} B^{\prime}$ marked on Fig. 1(f). The rest of the construction then proceeds as in Fig. 1(b). This method involves errors due to the restoration of a smooth curve by eye, and hence when the subsidiary faults have large throws the error may be large. The hangingwall in this case has been deformed by internal deformation so that a cross-check using the depth to décollement level calculation can no longer be used. 


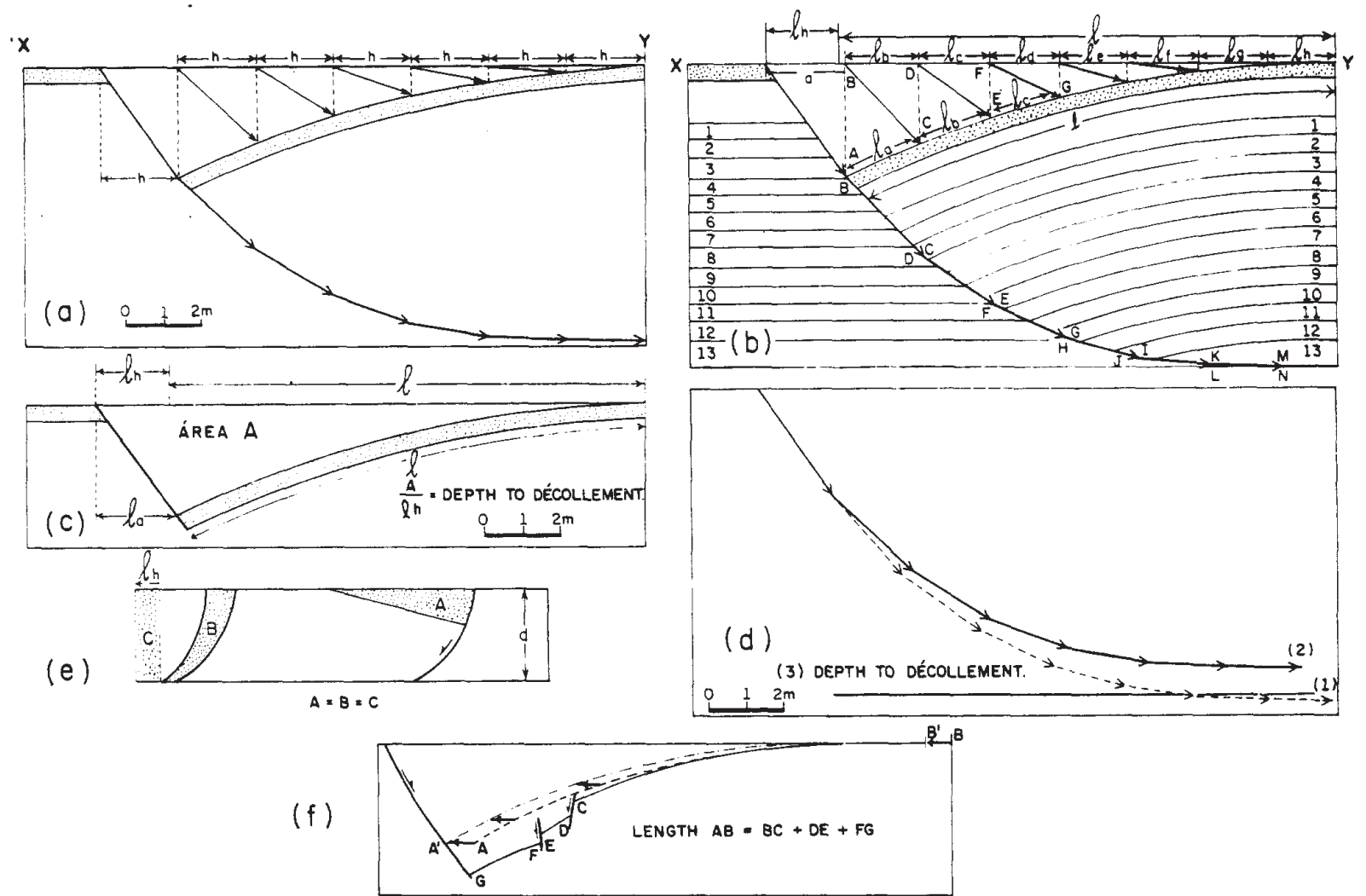

Fig. 1. (a) Similar fold bed-length balance technique first described by Verrall (1981). The heave $(h)$ on the fault is calculated, a grid of equal spacing to the heave is drawn out and the fault vectors constructed by joining the downthrown bed to the regional dip line $(X Y)$. The individual fault vectors are joined head-to-tail to produce the fault profile. (b) Flexural-slip and bed-length balance technique described in this paper for the same fault as in Fig. 1(a). See text for explanation. (c) Bed-length balance of the listric normal fault shown in Fig. 1(a) illustrating that the extension caused by faulting is not equal to the heave. Area $\mathrm{A} / \mathrm{lh}=$ depth to décollement level. Full explanation in the text. (d) Comparison of fault profile calculated using Verrall's technique (2) and calculated using the method described in this paper (1). The depth to decollement level using area balancing is also shown (3). Full explanation in the text. (e) The extended area at the left end of the cross-section usually has a complicated shape which includes angular shear (B). In this case the depth to décollement level, calculated using the equation given in Fig. I(c). is usually an overestimate. In a flexural-slip model the excess area at the end of the section should have the same shape as area $C$. and an accurate calculation to depth of décollement level can be made (adapted from Gibbs 1983). (f) Calculation of listric fault profile with the development of it suhsidiary fault fan. The dashed line represents the marker bed after removal of the throw on the two subsidiary faults. The dot-dash line $A^{\prime} B^{\prime}$ is constructed by moving the curve $A B$ parallel to the regional dip until point $A$ touches the listric fault. The rest of the construction is the same as that giver in Fig. 1(b).

Acknowledgements - Financial assistance from the Secretaria de Minas e Energia, Bahia, is gratefully acknowledged. I warmly thank two anonymous referees for their incisive comments.

\section{REFERENCES}

Gibbs. A 1983. Balanced cross-section construction from seismic sections in areas of extensional tectonics. J. Struct. Geol. 5, 153-160.
Gibbs, A. 1984. Clyde field growth fault secondary detachment above basement faults in North Sea. Bull. Am. Ass. Petrol Geol. 68 1029-1039.

Wernicke, B. \& Burchfiel, B. C. 1982. Modes of extensional tectonics J. Struct. Geol. 4, 105-115.

Verrall, P. 1981. Structural interpretation with applications to North Sea problems. Course notes. Joint Association of Petroleum Exploration Courses (JAPEC), London. 